\title{
NOx Control Options and Integration for US Coal Fired Boilers
}

\section{Quarterly Progress Report}

\author{
Reporting Period Start Date: January 1,2001
}

Reporting Period End Date: March 31,2001

\author{
Mike Bockelie, REI \\ Marc Cremer, REI \\ Kevin Davis, REI \\ Bob Hurt, Brown University \\ Eric Eddings, University of Utah
}

April 30, 2001

DOE Cooperative Agreement No: DE-FC26-00NT40753

Reaction Engineering International

77 West 200 South, Suite 210

Salt Lake City, UT 84101 


\section{Disclaimer}

"This report was prepared as an account of work sponsored by an agency of the United States Government. Neither the United States Government nor any agency thereof, nor any of their employees, makes any warranty, express or implied, or assumes any legal liability or responsibility for the accuracy, completeness, or usefulness of any information, apparatus, product, or process disclosed, or represents that its use would not infringe privately owned rights. Reference herein to any specific commercial product, process, or service by trade name, trademark, manufacturer, or otherwise does not necessarily constitute or imply its endorsement, recommendation, or favoring by the United States Government or any agency thereof. The views and opinions of authors expressed herein do not necessarily state or reflect those of the United States Government or any agency thereof." 


\begin{abstract}
This is the third Quarterly Technical Report for DOE Cooperative Agreement No: DE-FC2600NT40753. The goal of the project is to develop cost effective analysis tools and techniques for demonstrating and evaluating low NOx control strategies and their possible impact on boiler performance for firing US coals. The Electric Power Research Institute (EPRI) is providing cofunding for this program. This program contains multiple tasks and good progress is being made on all fronts. A Rich Reagent Injection (RRI) design has been developed for a cyclone fired utility boiler in which a field test of RRI will be performed later this year. Initial evaluations of RRI for PC fired boilers have been performed. Calibration tests have been developed for a corrosion probe to monitor waterwall wastage. Preliminary tests have been performed for a soot model within a boiler simulation program. Shakedown tests have been completed for test equipment and procedures that will be used to measure soot generation in a pilot scale test furnace. In addition, an initial set of controlled experiments for ammonia adsorption onto fly ash in the presence of sulfur have been performed that indicates the sulfur does enhance ammonia uptake.
\end{abstract}




\section{Table of Contents}

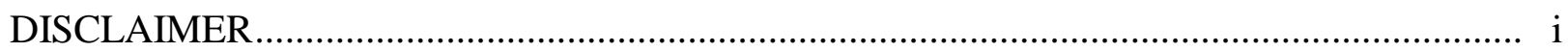

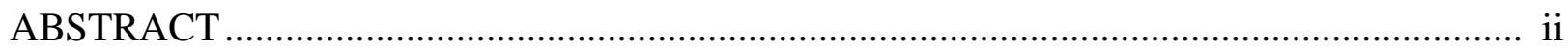

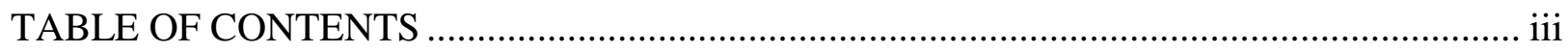

EXECUTIVE SUMMARY .................................................................................

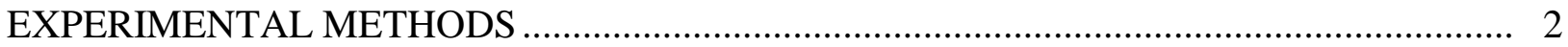

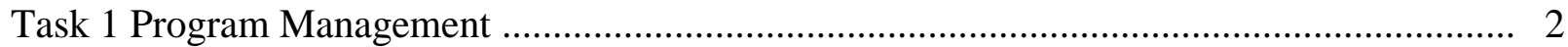

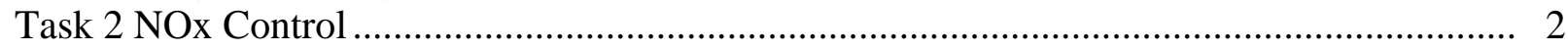

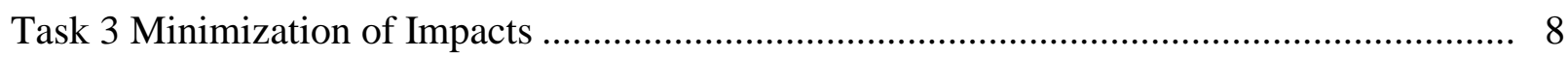

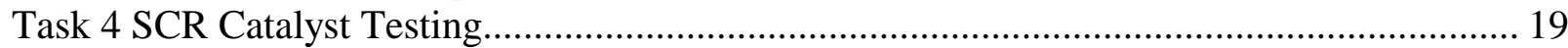

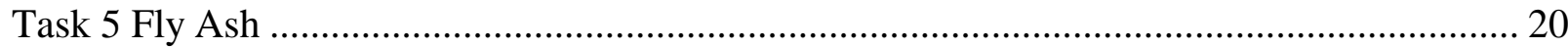

Task 6 Field Validation of Integrated Systems ......................................................... 21

RESULTS AND DISCUSSION ............................................................................. 21

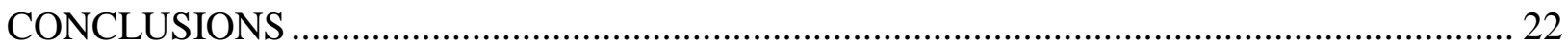

LITERATURE REFERENCES ........................................................................... 23 


\section{Executive Summary}

The work to be conducted in this project received funding from the Department of Energy under Cooperative Agreement No: DE-FC26-00NT40753. This project has a period of performance that started February 14, 2000 and continues through February 13, 2002.

Our program contains five major technical tasks:

- evaluation of Rich Reagent Injection (RRI) for in-furnace NOx control

- demonstration of RRI technologies in utility boiler scale field tests

- impacts of combustion modifications (including corrosion and soot)

- ammonia adsorption / removal from fly ash

- SCR catalyst testing

To date good progress is being made on the overall program. We have seen considerable interest from industry in the program due to our initial successful field tests of the RRI technology and the corrosion monitor.

During the last three months, our accomplishments include the following:

$>$ The injector locations for a Rich Reagent Injection (RRI) design have been specified for Ameren's Sioux Unit 1. This is a $488 \mathrm{MW}$, ten-barrel cyclone furnace with opposed wall firing. This unit is much larger than previous units for which RRI designs have been developed. Model predictions indicate that a 30\% reduction in NOx can be achieved with our RRI design. To provide for possible additional NOx reduction, additional ports for Selective Non-Catalytic Reduction (SNCR) reagent injection have also been prescribed. A field test of the RRI + SNCR design for this unit is scheduled for June, 2001.

$>$ Evaluations of RRI designs for two PC fired utility boilers have been performed. Initial results indicate the application of RRI to PC units will be more challenging than for cyclone fired units. A critical issue is developing an injection strategy that results in the furnace conditions required for amine enhanced NOx reduction to occur. The best performance achieved so far has involved a combination of in-burner injection and wall injection, which yielded a NOx reduction of $18 \%$ in a front wall fired unit.

$>$ Test procedures for calibrating a corrosion probe to monitor water wall wastage are being established. A field test of the corrosion probe is scheduled for next quarter. Preliminary modeling and experimental studies on the impact of soot generation for low NOx firing conditions have been performed. Further model improvements and measurements of soot generation in a pilot scale test furnace will be performed next quarter.

$>$ A request has been submitted to DOE for additional funds for an in-scope modification to our work plan for investigating SCR catalysts. The modified work plan would allow investigating the impact of biomass co-firing on SCR catalyst performance and including Prof. Larry Baxter (Brigham Young University) in the program. A decision by DOE for the proposed modified SCR effort is expected during the next quarter.

$>$ A set of controlled experiments for ammonia adsorption onto fly ash in the presence of sulfur have been performed that indicate the sulfur does enhance ammonia uptake. Additional tests will be performed to confirm the reproducibility of this result. 


\section{Experimental Methods}

Within this section we present in order, brief discussions on the different tasks that are contained within this program. For simplicity, the discussion items are presented in the order of the Tasks as outlined in our original proposal.

\section{Task 1 - Program Management}

\section{Industry Involvement}

On March 19, 2001, REI met with several EPRI staff members at the EPRI facility in Palo Alto, CA. The meeting was organized by our EPRI collaborators, Tony Facchiano, Dave O'Connor and Dave Broske. The purpose of the meeting was to provide EPRI Program Managers and Senior Technical Staff with an update on the work being performed on this project in order to identify means to coordinate the $\mathrm{R}+\mathrm{D}$ being performed on this project with other EPRI projects to ensure our research meets the needs of industry and to avoid duplication of effort. The meeting was structured around an overview of the program followed by detailed discussions and presentations for the on-going work effort for Rich Reagent Injection (RRI) and the corrosion monitor, the recently started research on soot formation under low NOx firing conditions and the planned research on SCR performance under biomass co-firing conditions.

\section{Task 2 - NOx Control - LNFS/SNCR/Reburning}

\section{Integrated System Design Analysis}

The focus of this sub-task is the application of REI's CFD modeling capability to the design of RRI injector systems for a full-scale boiler. The next scheduled field test is planned for summer 2001 at Ameren's Sioux plant. Sioux Unit 1 is a 488 MW opposed wall fired cyclone furnace equipped with ten 10-ft. diameter cyclone barrels firing a blend of Powder River Basin (PRB) and eastern bituminous coals. REI was contracted by Ameren to assess performance of RRI and SNCR in combination with RRI within Sioux Unit 1. These CFD simulations were used to determine suitable locations for the RRI ports so that they could be installed during the 2001 spring outage. A total of 20 locations were chosen for RRI injection and an additional 4 locations were chosen for possible installation of SNCR injectors. The CFD model results indicate that NOx reductions from 25-30\% should be achievable with RRI in this unit. Model results also indicate that an additional $25-30 \%$ NOx reduction should be achievable with SNCR trim, which would involve the use of 6 front and side wall injection ports. This work is still under progress to specify optimal nozzle characteristics.

More fundamental RRI modeling studies have been performed in parallel under this DOE program during the last quarter to improve our understanding of various NOx reduction processes including RRI, SNCR, fuel lean gas reburning, and combinations of these. This work has been aimed at gaining greater understanding concerning impact of flue gas temperature, flue gas stoichiometric ratio, and normalized stoichiometric ratio (NSR) on 
performance. A library of results of detailed chemical kinetics calculations is being constructed. Figures 2.1-2.4 show some of the results of these calculations which pertain to RRI conditions. In all cases, an Illinois No. 6 coal was used to determine the equilibrium mole fractions of coal combustion gases, which were then used in the kinetic calculations using CHEMKIN II ${ }^{\circledR}$. An isothermal plug flow reactor with a total residence time of $1 \mathrm{~s}$ was used in the calculations, but $\mathrm{NO}$ conversion was evaluated at $0.2 \mathrm{~s}$ in the results shown in the figures. With this approach, the NO conversion for a range of residence times can be investigated, with $0.2 \mathrm{~s}$ being approximately the residence time between the burners and the OFA ports in a utility boiler. From the figures, it can be seen that: (1) the initial NO level has a significant impact on the NO conversion efficiency; (2) the local stoichiometric ratio impacts the temperature range for which high NO conversion will occur; (3) in general, the maximum NO conversion occurs at a gas temperature of about 1700K; and (4) based solely on NO conversion, a NSR $=2$ appears to be "optimal".

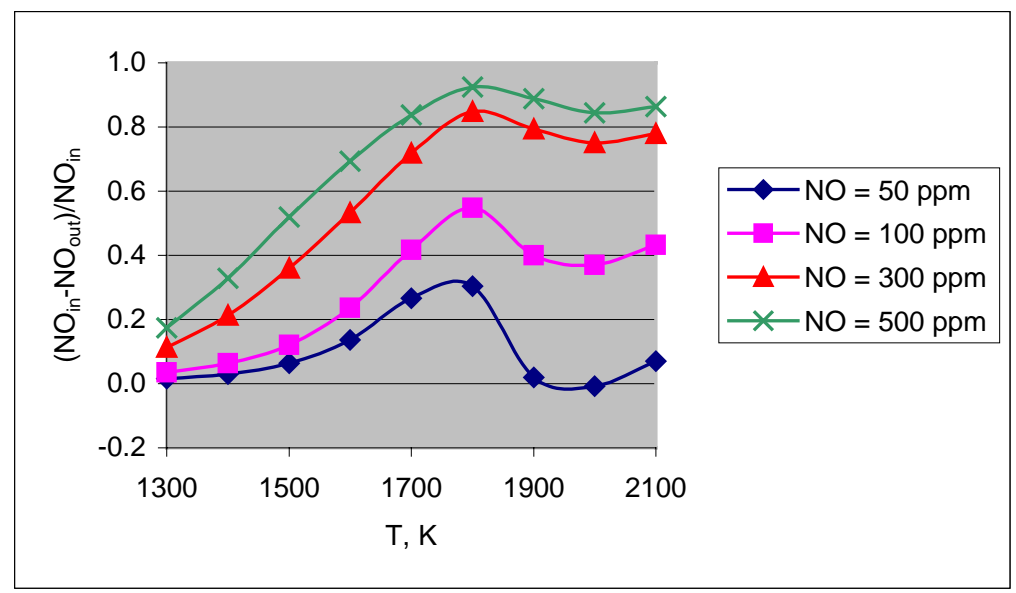

Figure 2.1: Effect of initial NO concentration on NOx conversion $(\mathrm{SR}=0.60, \mathrm{NSR}=2)$.

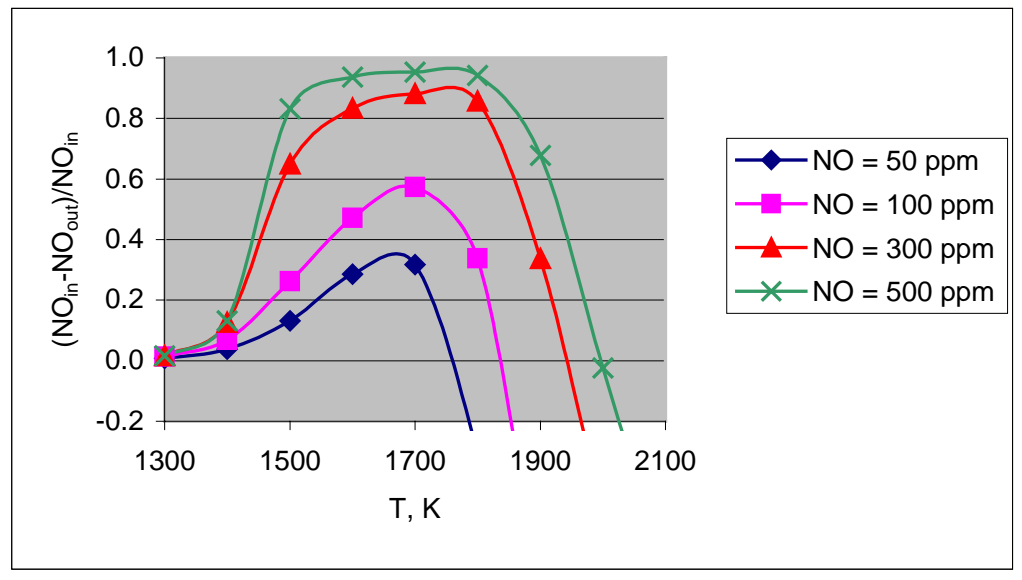

Figure 2.2: Effect of initial NO concentration on NOx conversion ( $\mathrm{SR}=0.98, \mathrm{NSR}=2)$. 


\section{4}

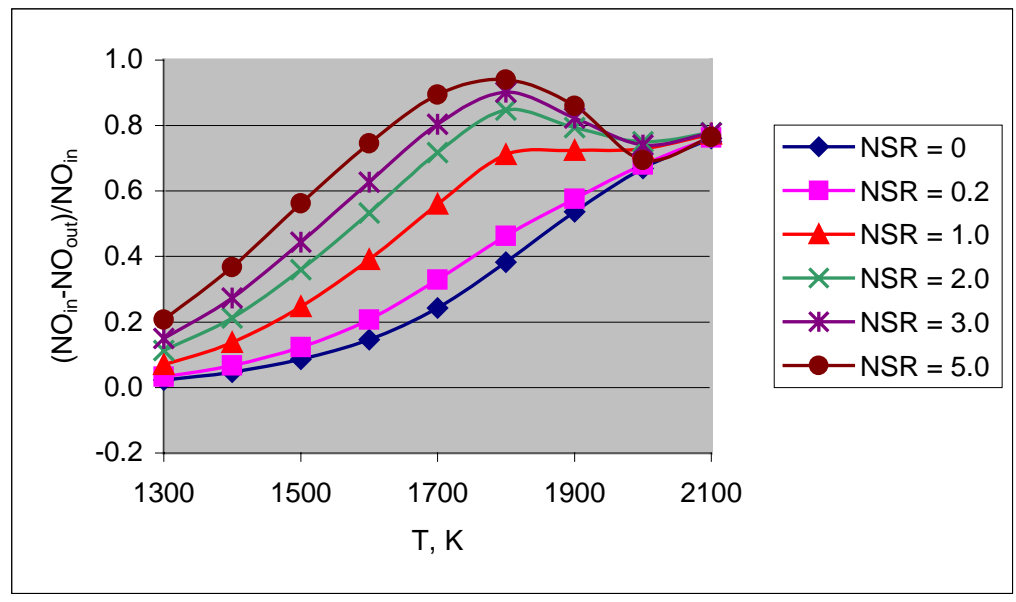

Figure 2.3: Effect of NSR on NOx conversion $\left(\mathrm{SR}=0.60, \mathrm{NO}_{\mathrm{in}}=300 \mathrm{ppm}\right)$.

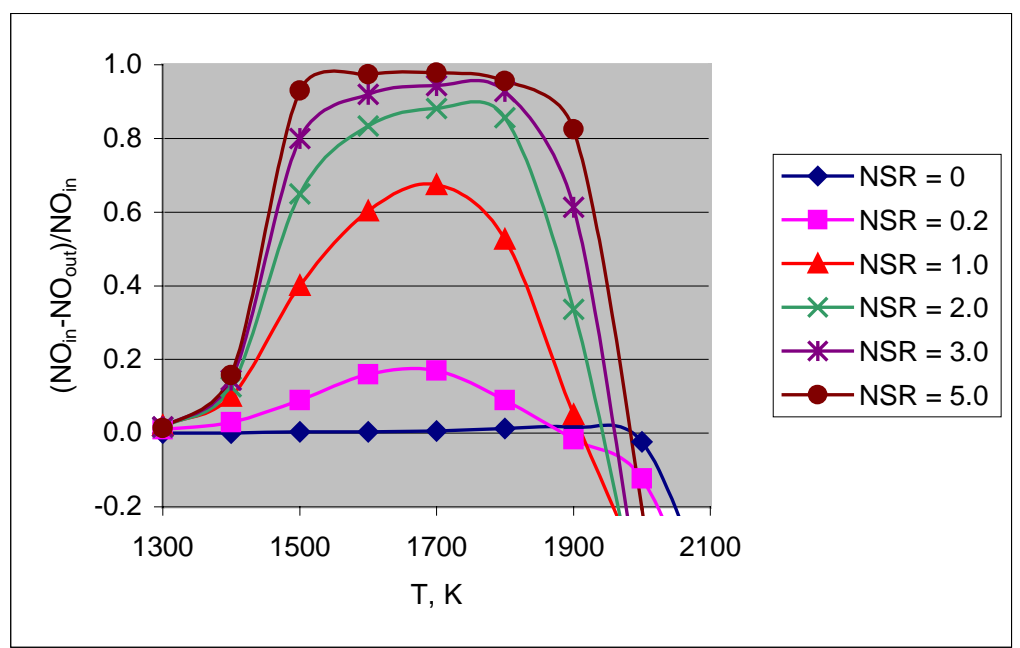

Figure 2.4: Effect of NSR on NOx conversion $\left(\mathrm{SR}=0.98, \mathrm{NO}_{\text {in }}=300 \mathrm{ppm}\right)$.

\section{Evaluation of Other NOx Control Options}

There is substantial interest within the utility industry to investigate the performance of RRI in a PC fired boiler, as a result of the RRI field tests previously conducted at B.L. England Station. An issue is whether RRI in a PC unit could provide NOx reductions similar to what has been predicted and measured at B.L. England (e.g., 30\%). PC fired boilers make up approximately $80 \%$ of the generating capacity associated with coal firing in utility boilers, so the potential payoff is quite large if RRI can be successfully demonstrated in a PC fired boiler. 
In the last quarterly report, a description of the modifications that were made to the CFD model to allow it to evaluate RRI in PC furnaces was given. The effort during this quarter has focused on investigating different reagent injection strategies within different classes of boilers. Our work on RRI in cyclone furnaces demonstrated that RRI performance is very sensitive to the time, temperature and stoichiometry in the local gas field through which the reagent droplets travel. Hence, we expect that different classes of boilers may require different approaches on how and where to inject the reagent. In the following sections we present an overview of our results for evaluating RRI in a front wall, coal fired furnace and an opposed wall, coal fired furnace

\section{RICH REAGENT INJECTION IN INDIAN RIVER UNIT 3}

Indian River Unit 3 is a 160 MW single-wall-fired coal boiler, which was retrofit with Riley low-NOx burners. Air was introduced, at normal operating conditions, through 4-level 16 burners, the overfire air (OFA) ports, the boundary air ports on the front wall, and side wall slots at the burner levels and at OFA level. The overall furnace stoichiometry was run at a value of $\mathrm{SR}=1.18$, with the burner stoichiometry run at a value of $\mathrm{SR}=0.85$.

Four rich reagent injection strategies, utilizing either rear wall injectors or in-burner injectors or both injectors, have been simulated. All four strategies utilized $10 \%$ urea solution at a NSR of 2.0. The results for these simulations are listed in the Table 2.1. The best NOx reduction achieved through RRI in these four strategies was approximately $18 \%$. Less than 2 ppm $\mathrm{NH}_{3}$ slip was observed for all rich reagent injection strategies.

Table 2.1: Rich Reagent Injection Simulation Results.

\begin{tabular}{|l|c|c|c|}
\hline & $\begin{array}{c}\text { NOx emission } \\
(\mathrm{ppm}, \text { wet })\end{array}$ & $\begin{array}{c}\mathbf{N H}_{3} \text { slip } \\
(\mathrm{ppm} \text {, wet })\end{array}$ & NOx reduction \\
\hline No RRI Baseline case & 193.2 & 0 & $\mathrm{~N} / \mathrm{A}$ \\
\hline RRI Strategy 1 - Rear wall injection & 172.7 & 1.5 & $10.6 \%$ \\
\hline RRI Strategy 2 - In-burner injection & 164.8 & 0.2 & $14.7 \%$ \\
\hline RRI Strategy 3 - Biased In-burner injection & 161.3 & 0.1 & $16.5 \%$ \\
\hline RRI Strategy 4 - Biased In-burner and rear wall injection & 158.5 & 0.5 & $18.0 \%$ \\
\hline
\end{tabular}

Figure 2.5 shows the baseline equivalence ratio distribution in the furnace, which shows that the best region for reagent release is near the rear wall where the flue gases are fuel rich. Figure 2.6 shows NOx distributions in the furnace for both no rich reagent injection case and four rich reagent injection strategies. 


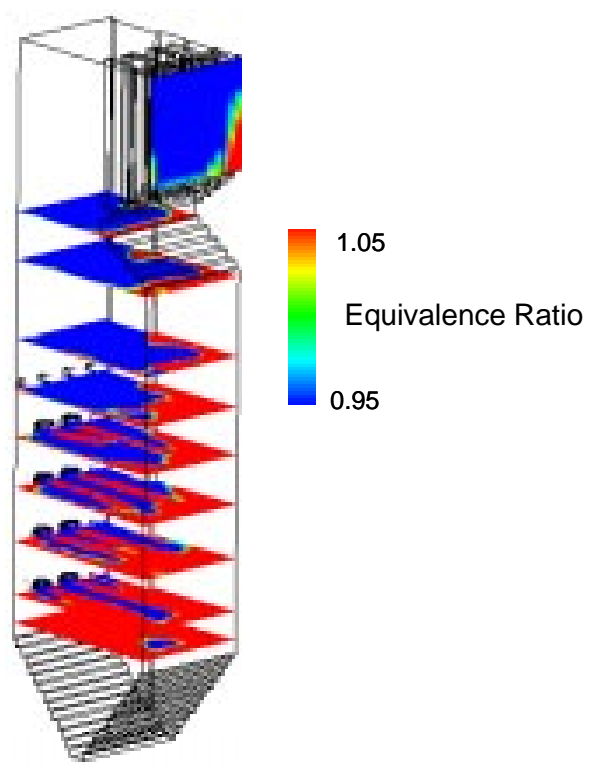

Figure 2.5: Predicted equivalence ratio distribution for the no RRI baseline case at Indian River Unit 3.

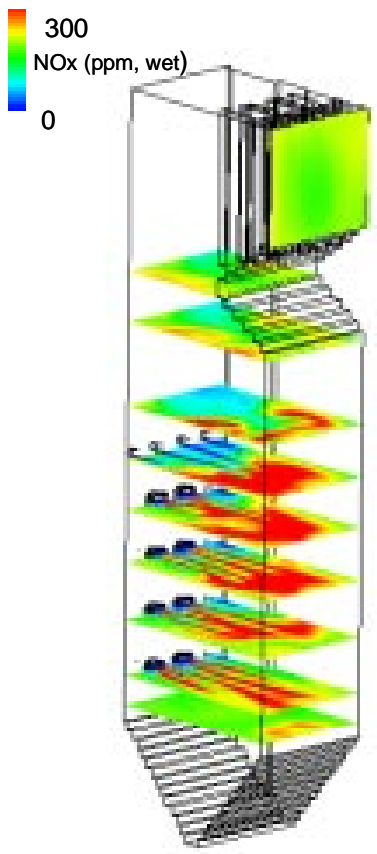

No RRI Basecase

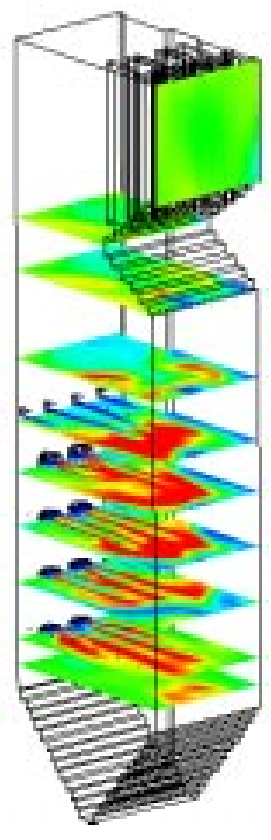

RRI Strategy 1

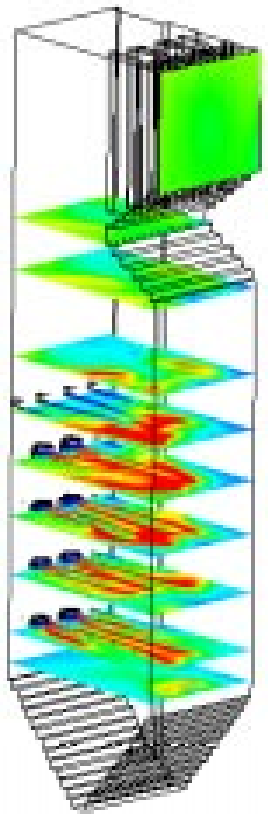

RRI Strategy 2

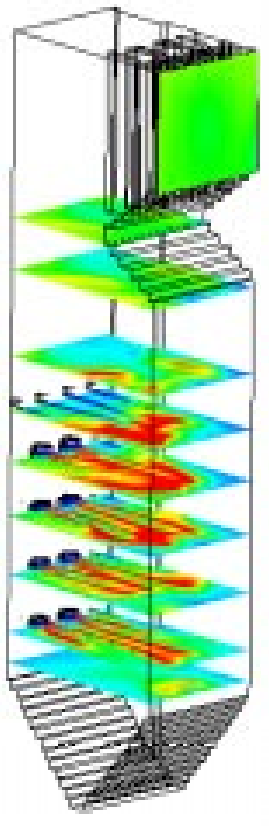

RRI Strategy 3

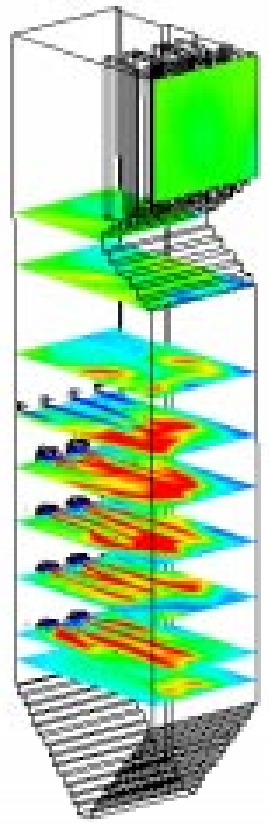

RRI Strategy 4

Figure 2.6: The predicted NOx distribution at Indian River Unit 3.

\section{RICH REAGENT INJECTION IN HAMMOND UNIT 4}

Hammond Unit 4 is a 500 MW opposed wall-fired boiler with 24 Foster Wheeler ControlledFlow/Split-Flame (CF/SF) burners. Two rich reagent injection strategies utilizing either side wall injectors or in-burner injectors were simulated. Both strategies utilized $10 \%$ urea 
solution, an NSR of 2.0, and an average droplet size of $100 \mu \mathrm{m}$. The results for the side wall injection strategy showed about $2 \%$ NOx reduction with about $17 \mathrm{ppm} \mathrm{NH}_{3}$ slip. The $\mathrm{NOx}$ reduction for the in-burner injection strategy showed approximately $7 \%$ NOx reduction with less than 1 ppm $\mathrm{NH}_{3}$ slip. The predicted NOx distribution in the furnace is shown in Figure 2.7 .

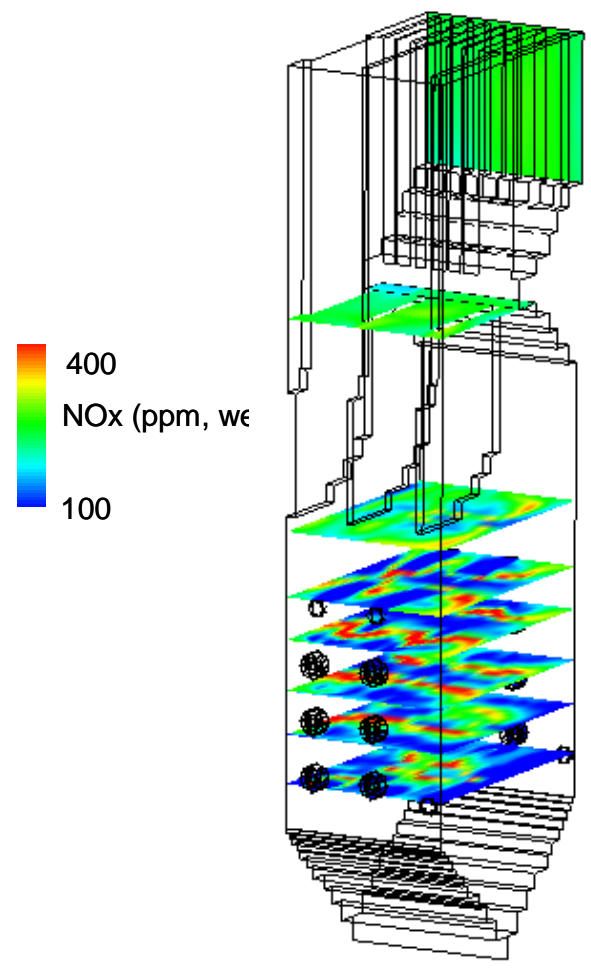

No RRI basecase

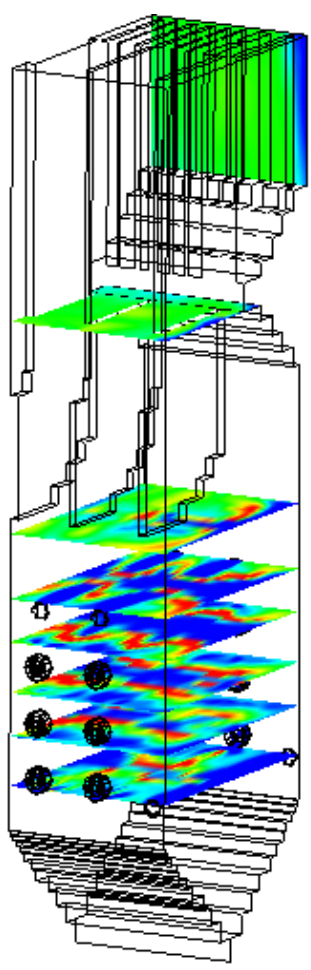

RRI side wall injection

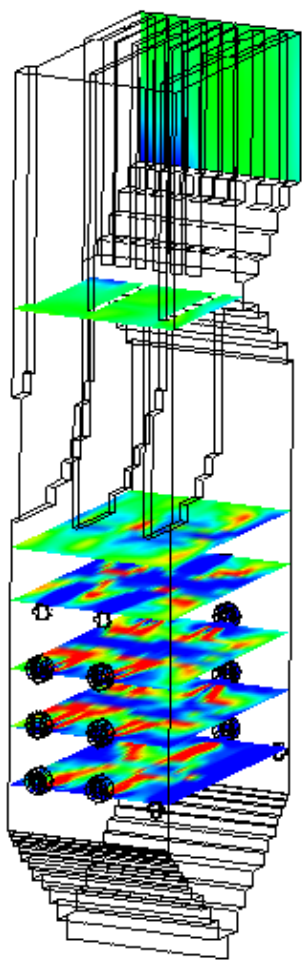

RRI in-burner injection

Figure 2.7: The predicted NOx distribution at Hammond Unit 4. 


\section{Task 3 - Minimization of Impacts}

\section{Task 3.1 Waterwall Wastage}

Work on the corrosion probe is centered in two areas: 1) fundamental studies to provide accurate corrosion probe calibration, and 2) preparation for full-scale testing at an eastern utility. Each of these areas will be discussed separately.

\section{CORRSION PROBE CALIBRATION TESTS}

REI's Electrochemical Noise (ECN) measurement approach is an advanced technique for monitoring corrosion online and in real-time. Traditionally, the electrochemistry of corroding metals has been measured by employing the Linear Polarization Theory (LPT). LPT relies on the application of a small polarizing DC electrical potential on an electrode. The resulting DC current through the electrode/fluid interface is measured. This current is related to the corrosion current, which is, in turn, related to the corrosion rate. A drawback of this method is that it requires the fluid to be conductive, limiting its applications to aqueous solutions. Another variation of this technique is based on the application of a small AC electrical potential to an electrode, that is the corroding metal, and the measurement of the resulting current. This technique is called Electrochemical Impedance Spectroscopy (EIS). The disadvantage of this method for corrosion monitoring is that it requires a build up of an ash layer on the electrode, for the method to work properly. This could take a considerable amount of time to establish and hence does not render the method attractive to continuous field-testing over short duration.

The ECN technique for corrosion monitoring does not require the application of a polarizing voltage. Instead it relies on the measurement of natural electrochemical current and voltage changes produced by the electrodes as a consequence of corrosion reactions at the metal surface. The standard deviation of the fluctuating voltage and current measured represent the potential noise and current noise. From these measurements a corrosion current is obtained and used to compute the corrosion rate. REI's corrosion probe has six sensor plates; three measure ECN, two measure electrochemical impedance (EI), and one is for temperature control as shown in Figure 3.1a-b.

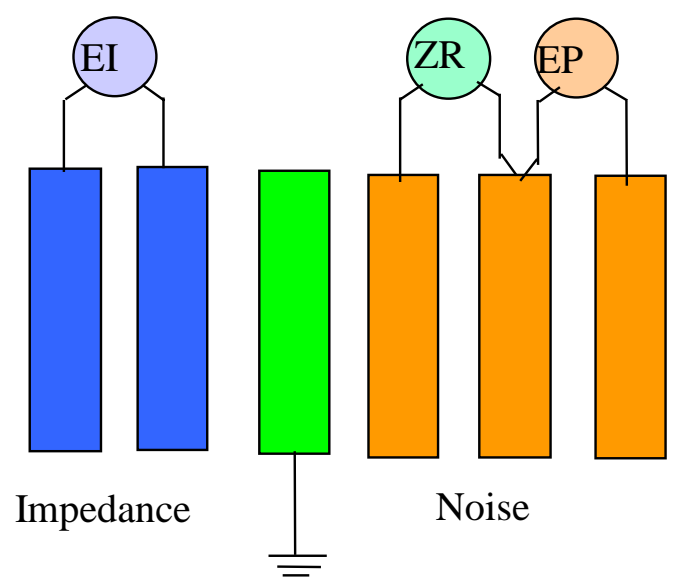

Figure 3.1a. Schematic of corrosion plates and their function. 


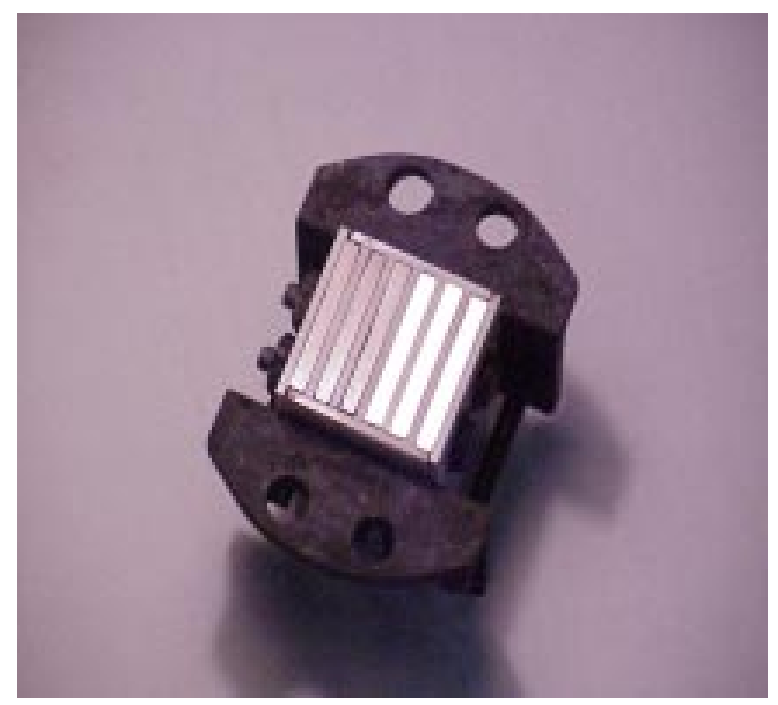

Figure 3.1b. Photograph of corrosion probe sensor head.

Although ECN has a rigorous fundamental basis, it has not been accepted by industry for corrosion measurements due to the lack of experimental evidence validating ECN predictions. For this reason, confirmation of the quantitative accuracy of this approach for a range of potential corrosion mechanisms and temperature ranges is necessary to provide confidence in the technology's use for the spectrum of useful applications in the high temperature, multiphase environment encountered in the furnace of a coal-fired boiler. For example, although theoretically this approach should work for corrosion of boiler tubes related to gas-phase sulfur and chlorine chemistry, there has been little substantiation based upon careful testing.

In order to provide confidence in the probe for all likely corrosion mechanisms, a set of carefully controlled laboratory experiments are under way for a range of stoichiometries, sulfur concentrations, chlorine concentrations, and temperatures that approximate the lower furnace environment that occurs in a coal-fired boiler. Figure 3.2 contains a subset of the matrix of 108 tests that we plan to perform. To create the desired environment, the experiments use a tube furnace, gas mixtures, and flow controllers, as shown in Figure 3.3.

We are proceeding by first running a set of eight tests for conditions that we expect to have high corrosion rates in order to confirm qualitative agreement between measured corrosion and corrosion rates predicted by ECN. At the completion of these initial tests we will then proceed to conduct the remaining tests in our test matrix. 


\section{0}

\begin{tabular}{|c|c|c|c|c|c|c|c|c|c|c|c|c|}
\hline & & \multicolumn{3}{|c|}{ Conc. (ppm) } & \multicolumn{7}{|c|}{ Flowrates $(\mathrm{mL} / \mathrm{min})$} & \multirow[b]{2}{*}{ Total } \\
\hline Run \# & Temp. C & $\mathrm{CO}$ & $\mathrm{H} 2 \mathrm{~S}$ & $\mathrm{HCl}$ & Cylin. 1 & Cylin. 2 & Cylin. 3 & Cylin. 4 & Cylin. 5 & Cylin. 6 & $\mathrm{H} 20$ & \\
\hline \multirow[t]{6}{*}{1} & 400 & 0 & 0 & 500 & 0 & 95.0 & 0.0 & 0.0 & 5.0 & 0.0 & 0.0044 & 100 \\
\hline & 450 & 0 & 0 & 500 & 0 & 95.0 & 0.0 & 0.0 & 5.0 & 0.0 & 0.0044 & 100 \\
\hline & 500 & 0 & 0 & 500 & 0 & 95.0 & 0.0 & 0.0 & 5.0 & 0.0 & 0.0044 & 100 \\
\hline & 400 & 0 & 0 & 2100 & 0 & 79.0 & 0.0 & 0.0 & 21.0 & 0.0 & 0.0044 & 100 \\
\hline & 450 & 0 & 0 & 2100 & 0 & 79.0 & 0.0 & 0.0 & 21.0 & 0.0 & 0.0044 & 100 \\
\hline & 500 & 0 & 0 & 2100 & 0 & 79.0 & 0.0 & 0.0 & 21.0 & 0.0 & 0.0044 & 100 \\
\hline \multirow[t]{12}{*}{2} & 400 & 0 & 500 & 500 & 0 & 92.5 & 0.0 & 0.0 & 5.0 & 2.5 & 0.0044 & 100 \\
\hline & 450 & 0 & 500 & 500 & 0 & 92.5 & 0.0 & 0.0 & 5.0 & 2.5 & 0.0044 & 100 \\
\hline & 500 & 0 & 500 & 500 & 0 & 92.5 & 0.0 & 0.0 & 5.0 & 2.5 & 0.0044 & 100 \\
\hline & 400 & 0 & 500 & 2100 & 0 & 76.5 & 0.0 & 0.0 & 21.0 & 2.5 & 0.0044 & 100 \\
\hline & 450 & 0 & 500 & 2100 & 0 & 76.5 & 0.0 & 0.0 & 21.0 & 2.5 & 0.0044 & 100 \\
\hline & 500 & $\underline{0}$ & 500 & 2100 & 0 & 76.5 & 0.0 & 0.0 & 21.0 & 2.5 & 0.0044 & 100 \\
\hline & 400 & 0 & 2100 & 500 & 0 & 84.5 & 0.0 & 0.0 & 5.0 & 10.5 & 0.0044 & 100 \\
\hline & 450 & 0 & 2100 & 500 & 0 & 84.5 & 0.0 & 0.0 & 5.0 & 10.5 & 0.0044 & 100 \\
\hline & 500 & 0 & 2100 & 500 & 0 & 84.5 & 0.0 & 0.0 & 5.0 & 10.5 & 0.0044 & 100 \\
\hline & 400 & 0 & 2100 & 2100 & 0 & 68.5 & 0.0 & 0.0 & 21.0 & 10.5 & 0.0044 & 100 \\
\hline & 450 & 0 & 2100 & 2100 & 0 & 68.5 & 0.0 & 0.0 & 21.0 & 10.5 & 0.0044 & 100 \\
\hline & 500 & 0 & 2100 & 2100 & 0 & 68.5 & 0.0 & 0.0 & 21.0 & 10.5 & 0.0044 & 100 \\
\hline
\end{tabular}

Figure 3.2. Representative test matrix for corrosion probe tests.

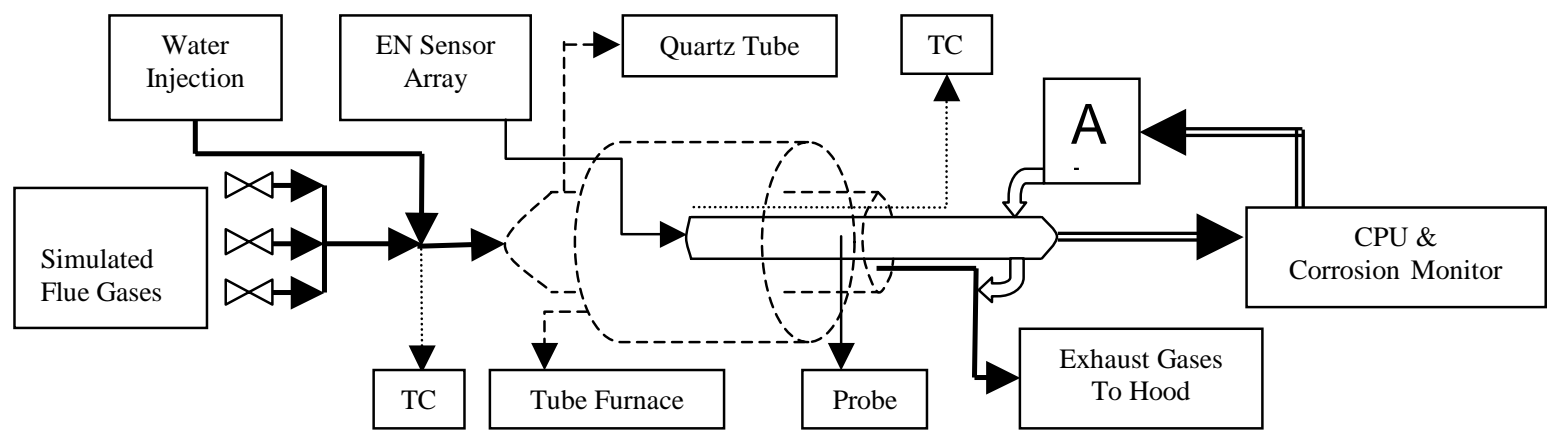

Figure 3.3. Experimental setup for corrosion probe tests. 
The challenging aspect of this effort is to devise an accurate calibration that can be performed in a timely manner. The approach that has been developed relies upon measurement of the volume of material lost by the actual sensor elements during the tests. As the tests are performed, the ECN signals are recorded as a function of time. The corrosion rate can then be numerically integrated as a function of time to determine the volume of material removed based upon the actual corrosion related reactions occurring. This can then be compared with the actual amount of material removed from the elements. The key feature of this approach is the volumetric measurement of material lost. In order to accomplish this the following procedure is used:

- The border of the sensor elements (1/16 in.) were sputtered and electroplated with nickel and chromel in order to form a protective layer that will remain unchanged in comparison with the steel surface during corrosion testing. However, it was found in our laboratory tests that the sputtered metals did not adhere tenaciously to the low-carbon steel plates. In particular when the corroded electrodes were cleaned in Clarke's solution (ASTM G1 - 81 Article 7.7), the sputtered border was also removed. Park et al., (1994) report that chromium and nickel alloys dissolve actively in hydrochloric acid. This has been a major setback. Further, it was observed by Dresselaers and Vandermeulen (1993) that even with a nickel coating as thick as 100 micron, the corrosion process can work its way underneath the nickel coating. This caused our 1 micron-thick border to flake off. Nevertheless, these problems have been overcome by welding the ends of the sensor plates with stainless steel 625, Inconel. Figure 3.4 shows the Inconel border after a corrosion test. Inconel is a nickel-chromiummolybdenum alloy that is high-temperature and corrosion resistant. This protective border is critical for calculating the change in volume.

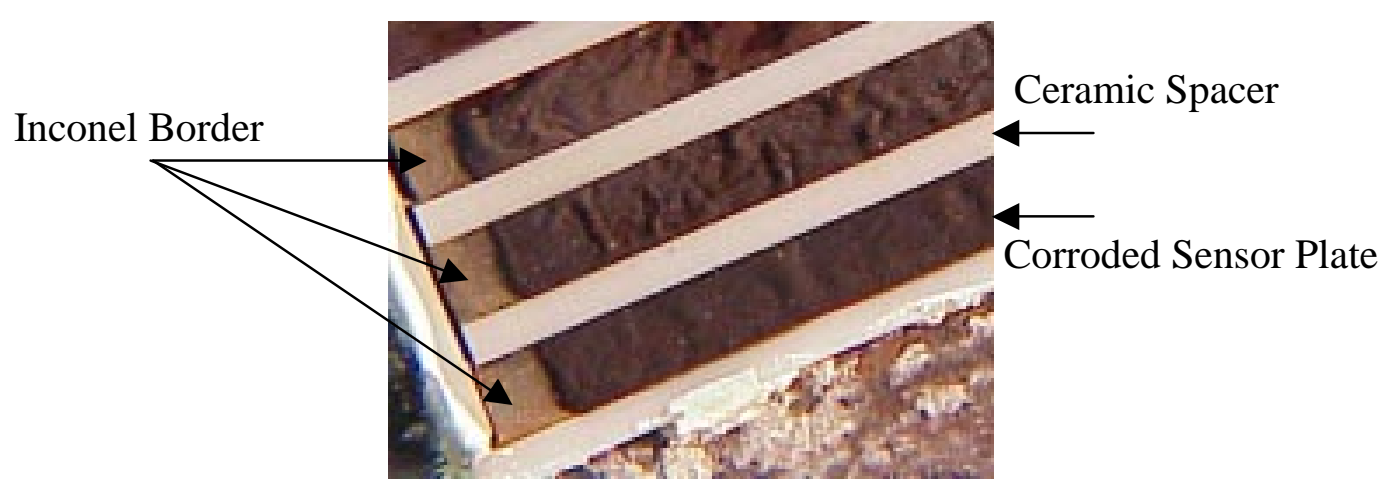

Figure 3.4. A close-up of the ECN sensor array after a corrosion test showing the Inconel border.

The sensor elements are polished to a mirror finish and then characterized using a KLA Tencor P-10 surface profiler. The profilometer uses a stylus with a tip a few microns in size. The stylus traces the surface of the element in 20-micron steps and records the height every 20 microns. (i.e., a height is recorded at every point on a 20 micron by 20 micron grid). Figures 3.5 and 3.6 show a scan and a graphic display of the face of a polished electrode scanned by the profilometer before it was exposed to a corrosive environment. The smooth surface finish is clearly discernible and it is hard to distinguish the Inconel border from the steel surface. 


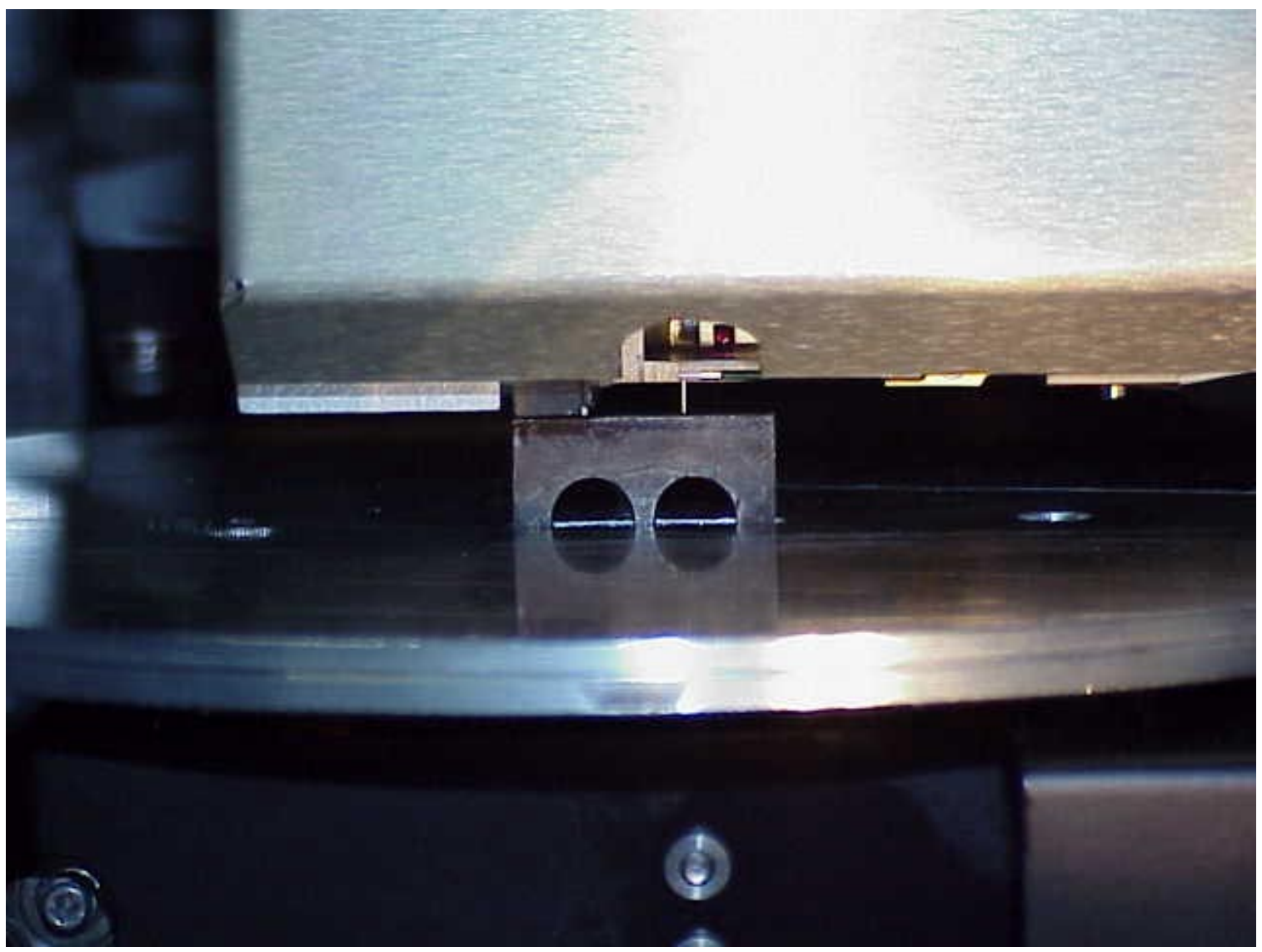

Figure 3.5. A sensor plate being scanned by the KLA-Tencor profilometer.

- Corrosion tests on the order of seventy-two hours are performed for a specific set of conditions. The probe is then disassembled and the sensor elements are cleaned with Clarke's solution, according to ASTM G1-81 7.7.2 and again characterized using the profilometer. Figures 3.7 and 3.8 show the profilometer scans of the same electrode of Figure 3.6 after a 72-hour exposure to a moist gaseous environment containing $2100 \mathrm{ppm} \mathrm{HCl}$ and $100 \mathrm{ppm} \mathrm{CO}$ at $500^{\circ} \mathrm{C}$. It may be noted that, in Figure 3.7, the corrosion depth along the Inconel/electrode interface (the inter-welding zone) is of the same order of magnitude as that found elsewhere on the corroding electrode surface. It can also be inferred from this figure that uniform corrosion took place during the test run. There is clearly no evidence of localized corrosion.

- The cleaning solution may also wash away some metal from the plate. This is accounted for in our procedures by correcting for profilometer depth caused by acid washing. 


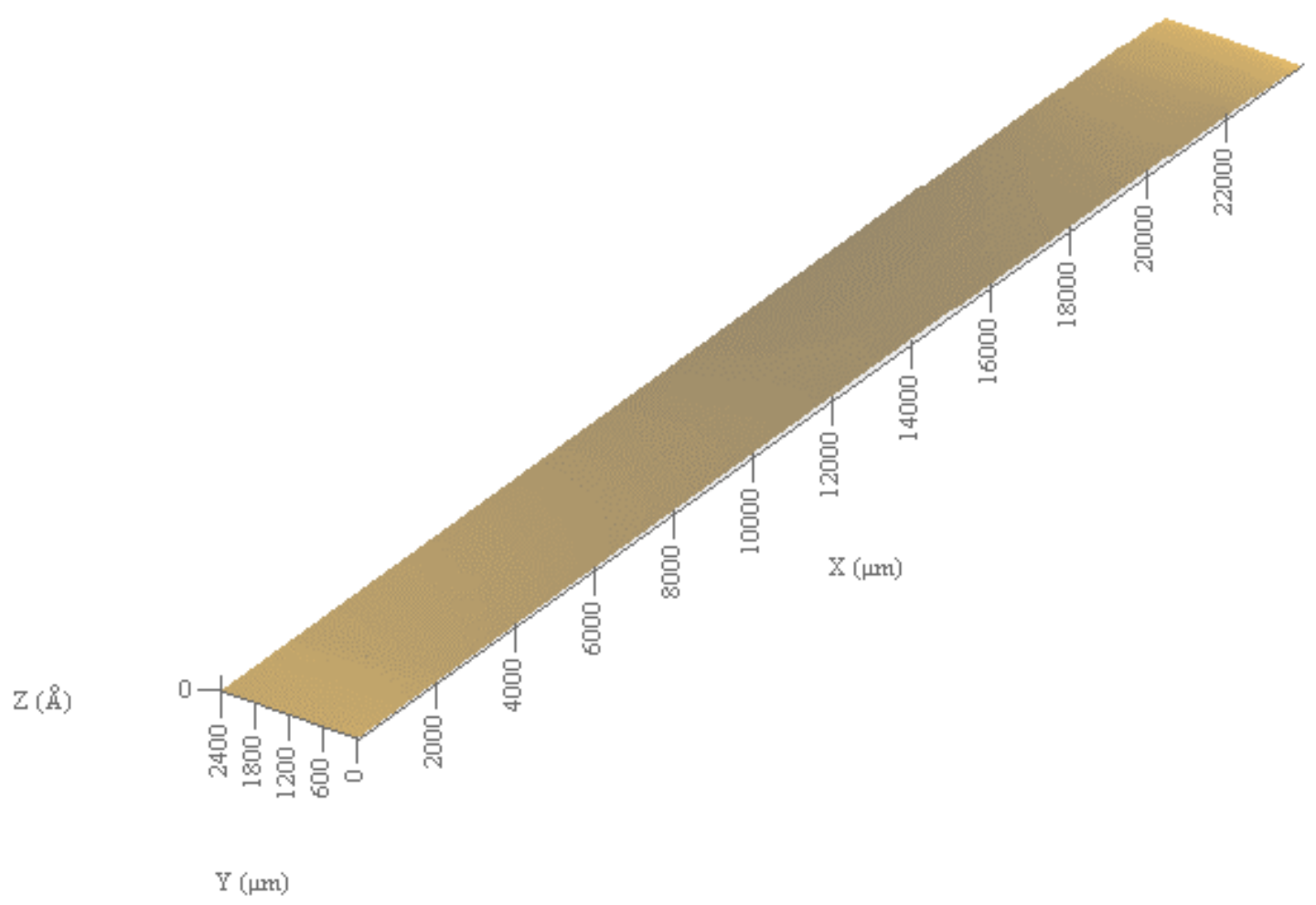

Figure 3.6. Surface profile of a polished electrode face before exposure to a corroding environment.

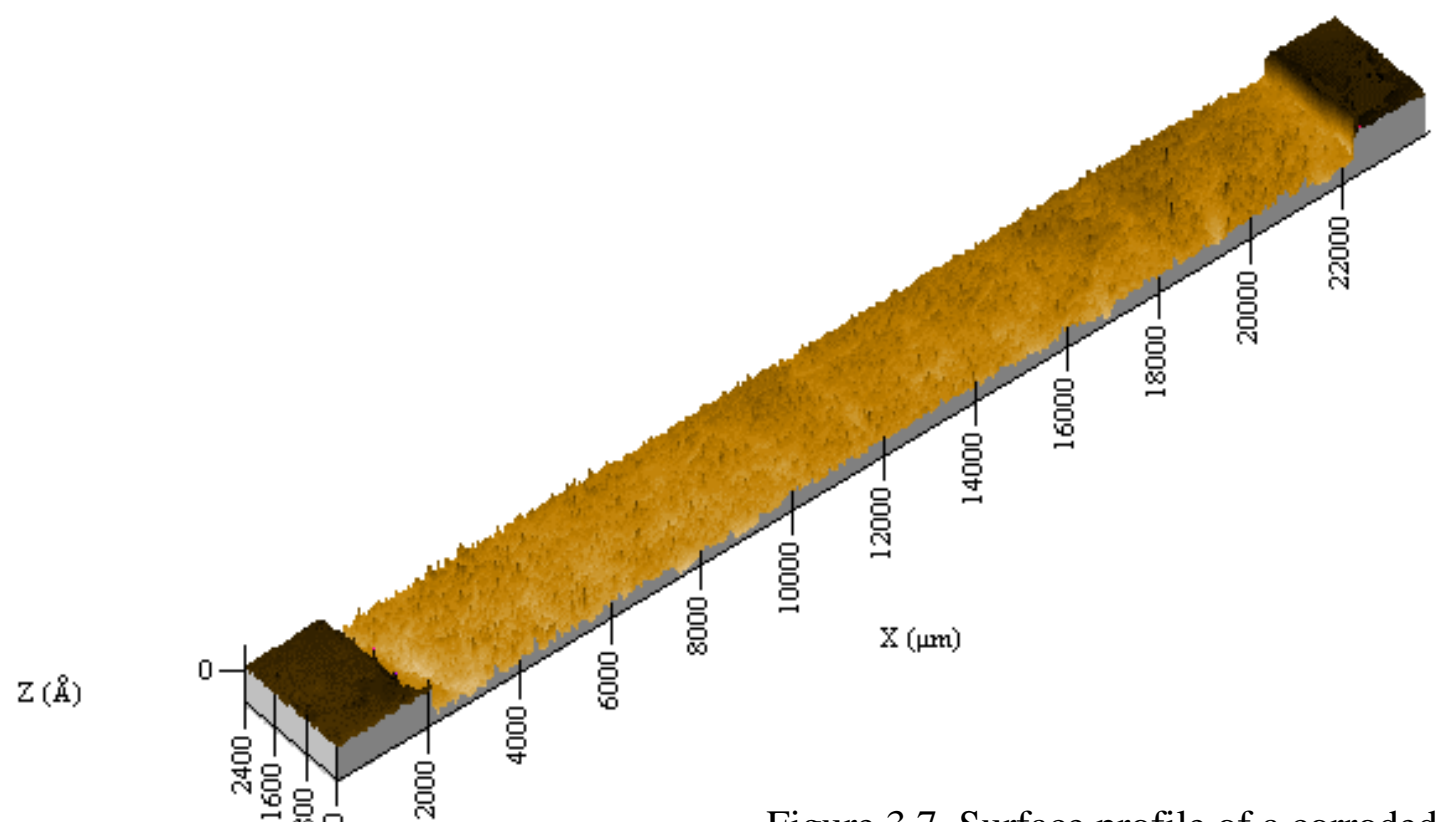

Figure 3.7. Surface profile of a corroded electrode face showing the Inconel border at the left and right edges. 


\section{4}

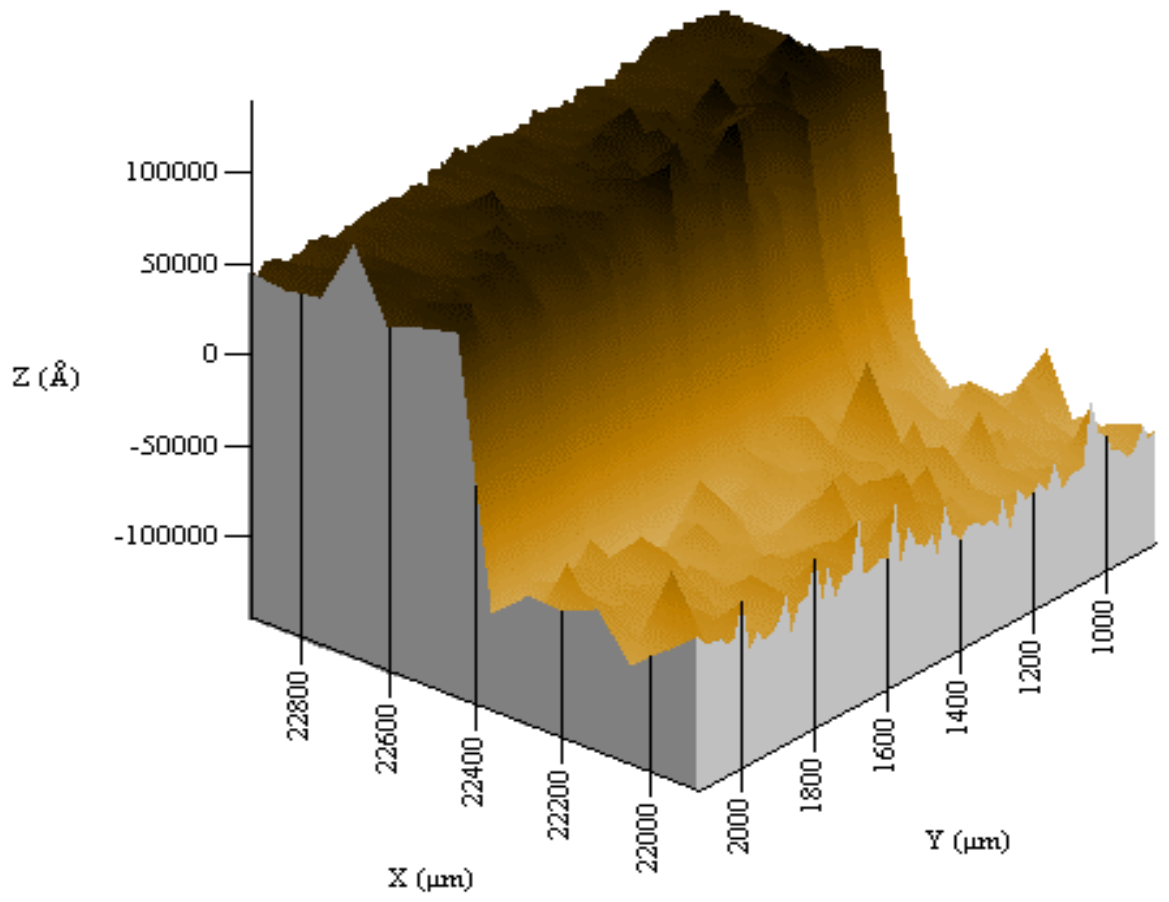

Figure 3.8. Surface of a corroded electrode showing a close up of the border region where the Inconel is unaffected by corrosion and the steel plate has recessed by about 10 micron.

- Software written specifically for this purpose is then used to define a basis plane and determine the volume of surface material removed during the test.

- A surface of the element is mechanically polished flat and reinserted for the next experimental run.

Because ECN signals are weak and hence susceptible to electromagnetic radiation interference from AC power sources; a Faraday cage has been provided to minimize the pickup of extraneous signals. Interference may also be caused by corrosion on the backside of the plates. Cooling the plates with dry air and coating them with a high temperature, corrosion resistant film minimizes the potential for corrosion at the rear end of the plates.

The amount of material removed by corrosion during a brief test is extremely small. Conventional efforts using corrosion coupons require periods of months or longer to obtain accurate determinations of a corrosion rate. The use of a high-resolution profilometer, careful techniques for mounting the piece to be analyzed, and software designed to compare the sensor element surface before and after testing, has the potential to quantify material loss sustained over short periods of corrosion monitoring. 
The development and verification of this procedure are underway and the calibration tests should be completed during the next quarter. Figure 3.9 is an example of the probe signal for ECN corrosion rate for the test electrode presented in Figure 3.7. In this figure, the light colored (green) line with high frequency variations is the recorded corrosion rate. The dark solid (blue) line is a moving average of the recorded corrosion rate.

Plotted in Figure 3.10 are the results of a corrosion run involving a gaseous environment containing $\mathrm{CO}$ and moisture. Both the ECN and the EIS corrosion rates are displayed. As expected, the test run in an $\mathrm{HCl}$ environment (Figure 3.9) exhibits higher corrosion rates than those in a $\mathrm{CO}$ environment (Figure 3.10) maintained at the same operating temperature. More tests and analysis of results are currently in progress. These will produce a comprehensive calibration of the corrosion-monitoring probe.

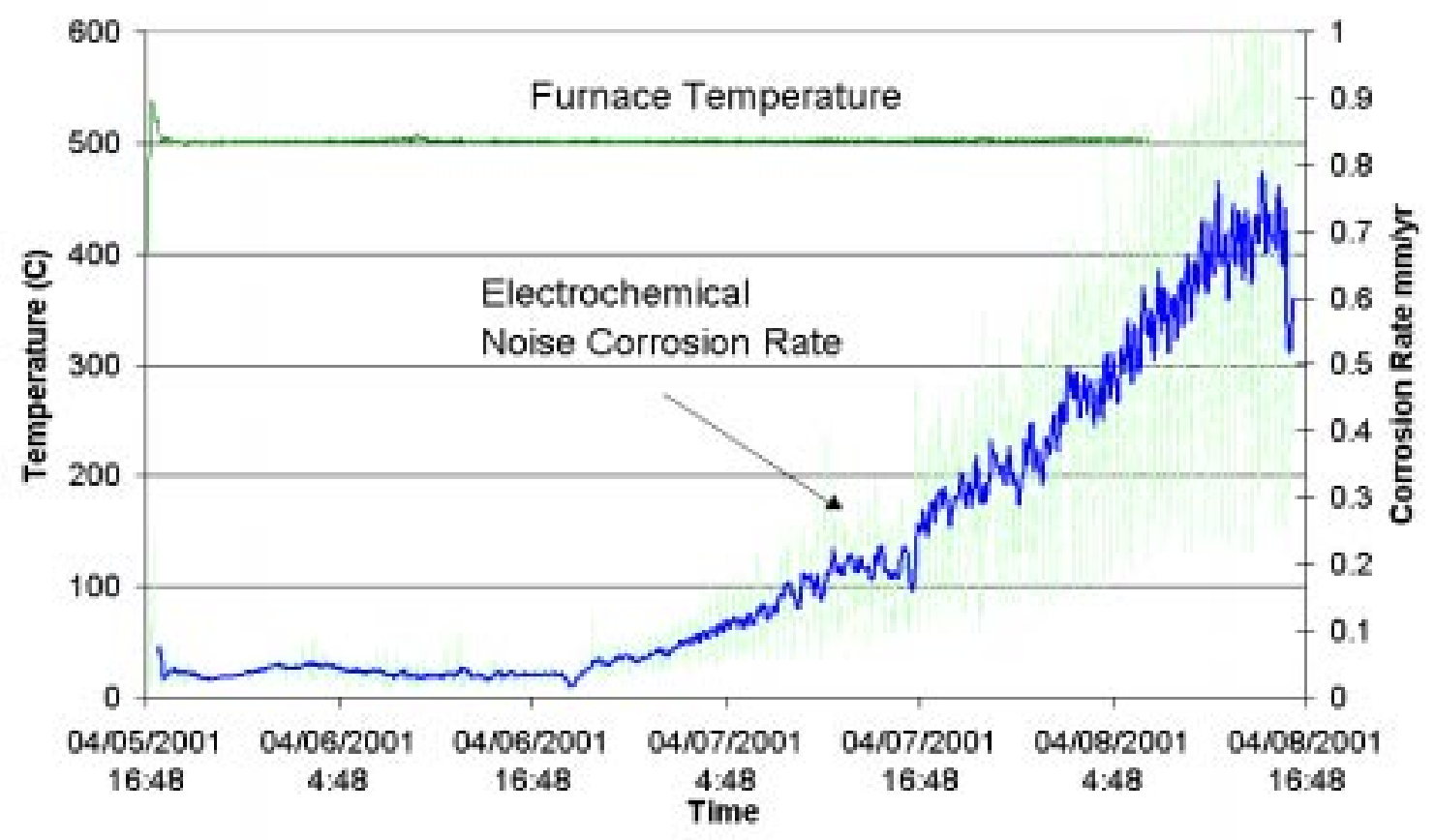

Figure 3.9. Electrochemical noise corrosion rate from a run in an experiment with $2100 \mathrm{ppm} \mathrm{HCl}$ and $100 \mathrm{ppm} \mathrm{CO}$ at $500^{\circ} \mathrm{C}$. 


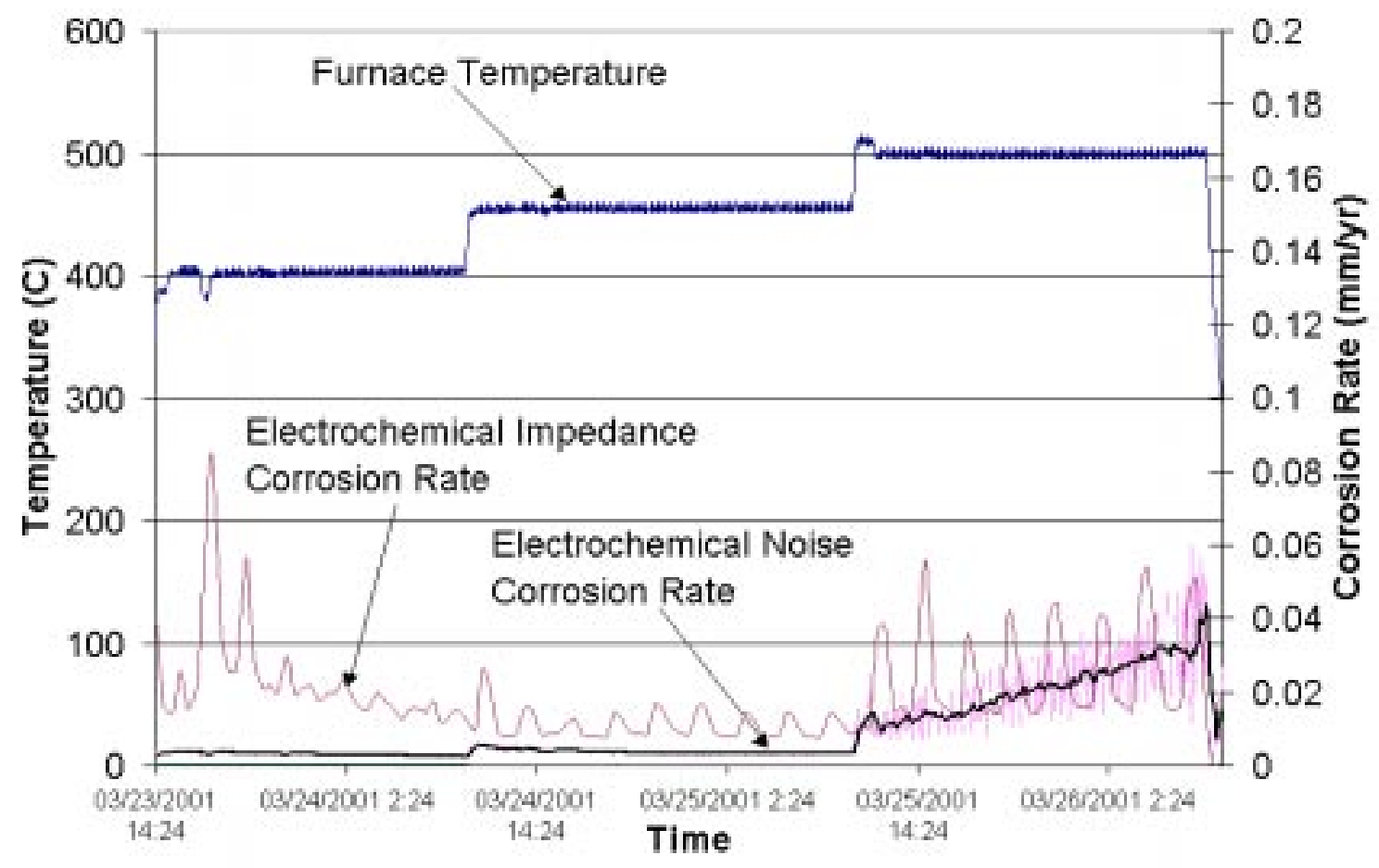

Figure 3.10. Electrochemical noise and electrochemical impedance corrosion rates from a run with $100 \mathrm{ppm} \mathrm{CO}$ in the temperature range of 400 to $500^{\circ} \mathrm{C}$.

\section{FULL SCALE TESTING}

Full-scale boiler testing in which we perform corrosion measurements using the corrosion probe is planned for later this year. Our plans call for testing at the FirstEnergy Eastlake plant in May, 2001 and the Ameren Sioux plant in August, 2001.

In planning for the full-scale tests, it became obvious that there would need to be some modifications to the existing probe before it could be efficiently used in a power station boiler. Some of these modifications include:

* Easier method of installing the six corrosion plates

Better control on the cooling air

* All cables, cooling, temperature measurements, etc. must connect at the very end of the probe, nothing can exit or enter from the side of the probe

* Spool pieces will be needed for the probe since measurements will have to be made with the probe passing through a 9-foot duct.

* Computer software improvements 


\section{7}

This quarter design changes to the probe hardware, not the probe measuring head or technique, were prepared. Work has begun on modifying the electronics of the probe to include a smaller, more compact equipment case. Also, the back end of the probe has been redesigned to permit all cables and cooling circuits to enter/exit.

The computer software has been upgraded by our partner, Corrosion Management and is currently working much better.

For the field test at the Sioux Plant, the probe will have to pass through the secondary air plenum. This is not real hot $\left(\sim 315^{\circ} \mathrm{C}\right)$, but will require that spool pieces be built to accommodate this environment.

\section{Task 3.2 Soot}

\section{MODELING}

A soot model originally developed by Fletcher [Fletcher et al, 1992], [Brown \& Fletcher, 1998] has been implemented into REI's two phase combustion CFD code GLACIER. In this model, it is assumed that coal soot forms only from tar. The model is comprised of three transport equations for tar mass fraction, soot volume/mass fraction, and soot number density [Brown \& Fletcher, 1998]. Tar evolution is calculated from the Lagrangian particle phase equations that use the CPD model to determine devolatilization rates and tar yields [Fletcher et al, 1992].

A simple drop tube test case has been run with Fletcher's soot model implemented into GLACIER. As shown in Figures 3.11a-d, the simulation predicts reasonable soot volume fractions, on the order of $10^{-6}$, with the highest concentration occurring in the fuel rich region (i.e., along the center of the drop tube). However, as shown in Figure 3.11e, the model predictions also highlight some deficiencies in the model because it predicts a non-zero soot number density in regions where the soot mass fraction is zero. This behavior has been previously reported by Brown (1997). In private communications, Fletcher has suggested model modifications that should eliminate this non-physical behavior and lead to a more robust model.

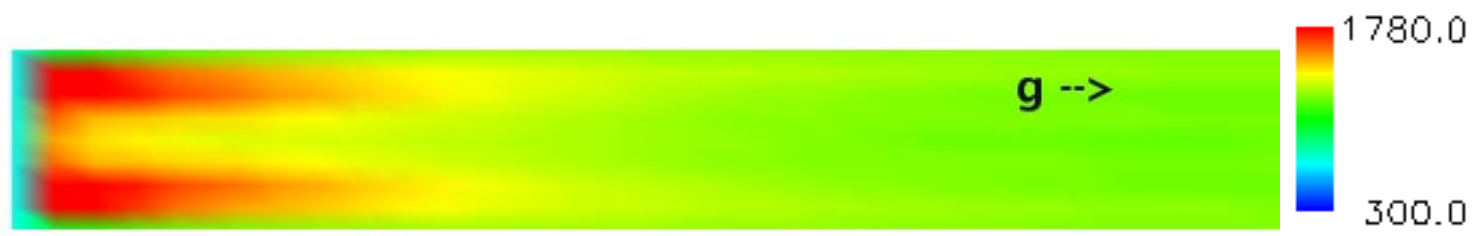

Figure 3.11a. Gas temperature (K).

Arrow shows the direction of gravitational force $(\mathrm{g})$.

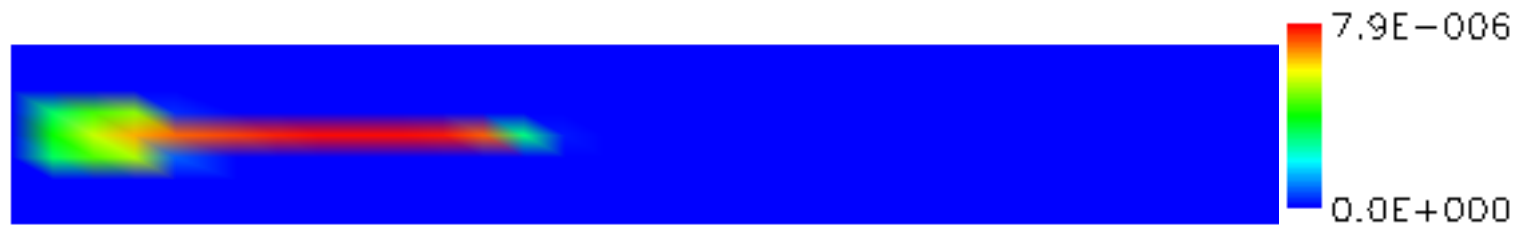

Figure 3.11b. Soot volume fraction. 


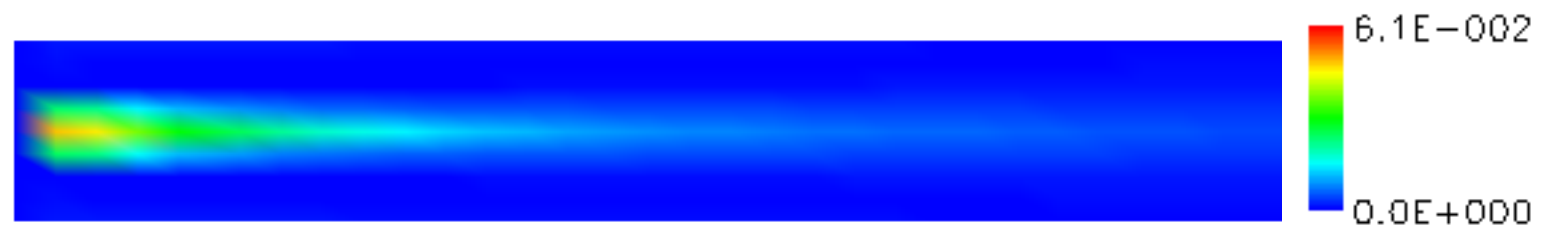

Figure 3.11c. Tar mass fraction.

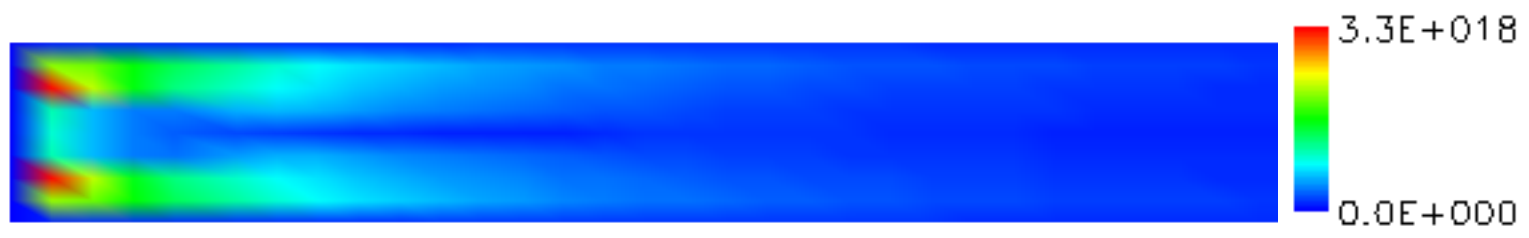

Figure 3.11d. Soot number density.

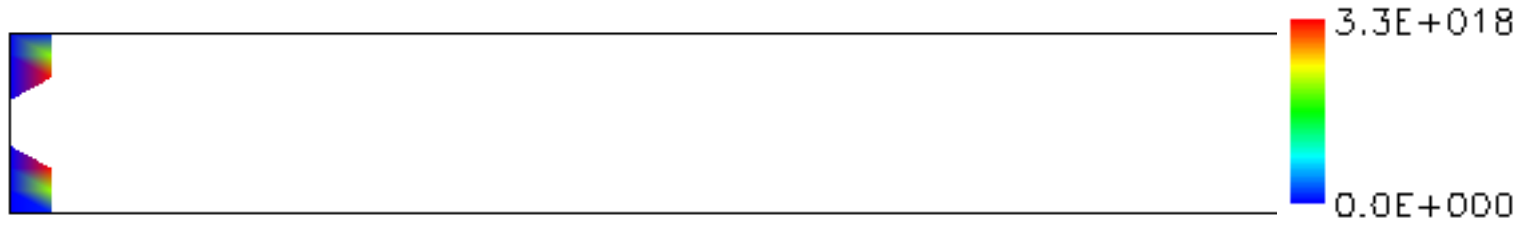

Figure 3.11e. Soot number density shown only in the region in which soot volume fraction equals zero.

\section{EXPERIMENTAL WORK}

A series of experiments for low NOx firing conditions will be performed in the L1500 (4.5 mmBTU) pilot scale test furnace at the University of Utah Combustion Research Laboratory (CRL) in May, 2001. The purpose of the tests is to (1) verify the presence of soot for certain firing conditions and (2) provide experimental data to use in verification of the soot model implemented into our CFD code. During the last quarter, shakedown tests have been performed using a pool-fire facility at the University of Utah. These tests allowed gaining familiarity with the experimental equipment and data collection procedures that will be used in the L1500 tests (e.g., sampling probe, dilution chamber, and photo acoustic spectroscopy (PAS) system). Illustrated in Figure 3.12a is a pool fire with a sampling probe. The sampling probe is a transpiration probe with $\mathrm{N}_{2}$ quench and water cooling, which is attached to a dilution chamber followed by the PAS system. Dilution is necessary due to a limitation of the PAS system. Figure $3.12 \mathrm{~b}$ shows a soot concentration along the fire centerline, rim and half way between the centerline and rim as a function of height from the fuel surface. The results show reasonable trends. However, because the dilution factor has not been calibrated the reported soot concentration magnitude is somewhat low. 


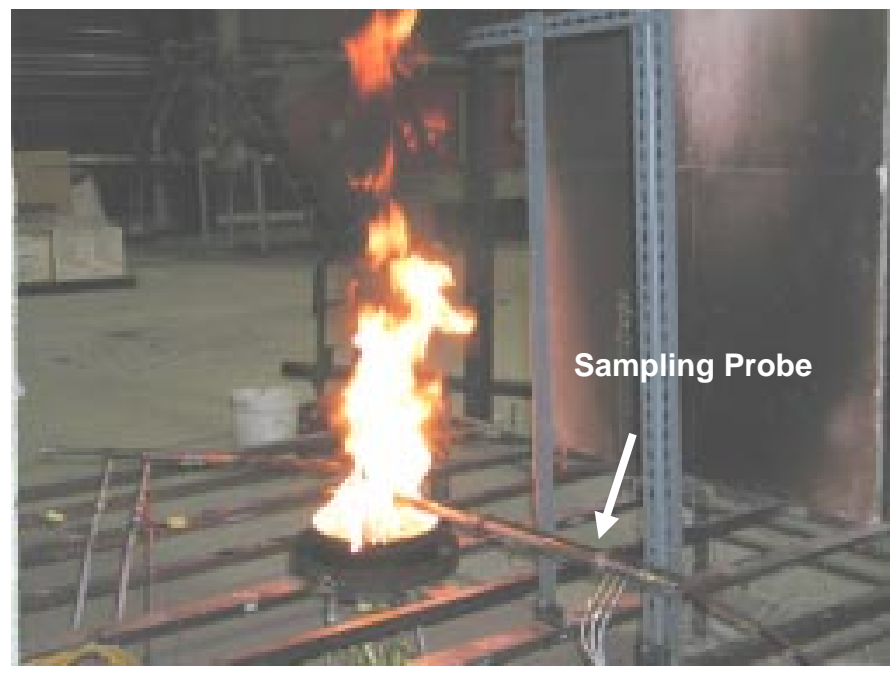

Figure 3.12a. Pool fire with Jet A fuel.

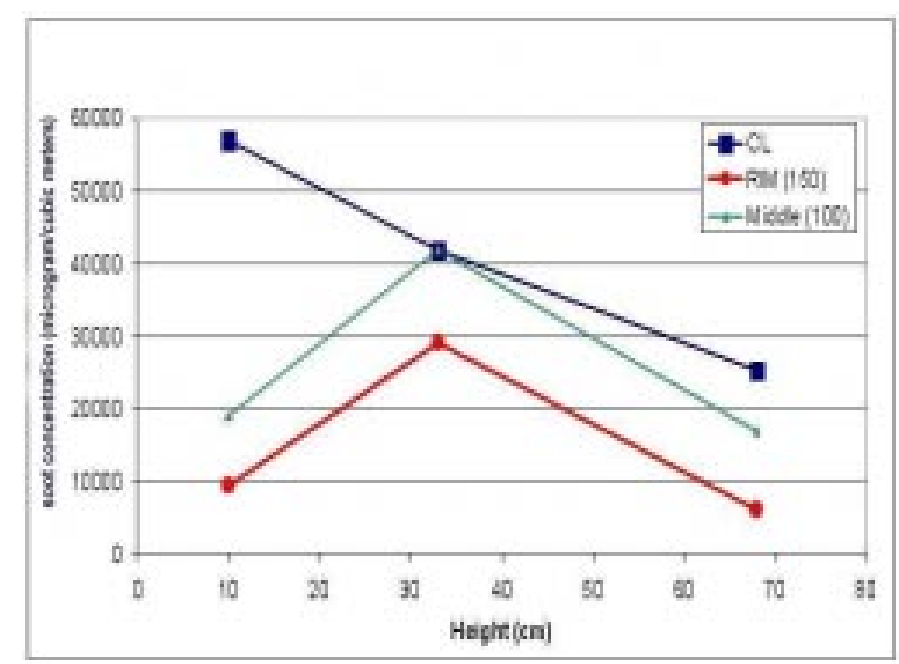

Figure 3.12b. Soot concentration at center, rim, and middle of pool fire.

\section{Task 4 - SCR Catalyst Performance under Biomass Co-Firing}

The cost and effectiveness of NOx control strategies for coal-fired boilers has received considerable attention over the last two decades and a number of successful approaches have been applied. Utilities must weigh a number of issues when determining the best strategy for their specific units. Comparisons routinely include cost and the amount of NOx reduction, with selective catalytic reduction (SCR) often used as a standard for comparison. However, in order to make this comparison meaningful, the total cost of combustion modifications must be considered (carbon-in ash levels, waterwall wastage, etc.). Industry is developing experience evaluating many of these costs and it is one of the tasks of this program to better understand two such areas - waterwall corrosion and soot formation. For SCR, the "real" cost for coal-fired boilers using US coals and coal/biomass blends is very uncertain.

Discussions with DOE/NETL personnel resulted in REI submitting a request for additional DOE funds to support an in-scope modification to our original work plan for investigating SCR issues. The modified work plan would allow including Prof. Larry Baxter (Brigham Young University) in the program. The modified work plan would allow us to evaluate SCR costs at a deeper level and to improve estimates of actual costs. The proposed new tasks include:

1. technology assessment on fundamental analysis of chemical poisoning of SCR catalysts by alkali and alkaline earth materials;

2. evaluation of commercial catalysts in a continuous flow system that simulates commercial operation;

3. evaluating the effectiveness of catalyst regeneration; and

4. develop a model of deactivation of SCR catalysts suitable for use in a CFD code. Authorization from DOE for the proposed modifications to our SCR task is expected during the next quarter. 


\section{Task 5 - Fly Ash Management/Disposal}

This task deals with the undesirable adsorption of ammonia on fly ash associated with the operation of advanced NOx control technologies such as selective catalytic reduction. The task examines the fundamentals of the adsorption process as well as the fundamental process underlying potential techniques for post-combustion removal of adsorbed ammonia. This task is being performed at Brown University under the leadership of Prof. Bob Hurt.

Work this period focused exclusively on Subtask 5.1: Ammonia Adsorption Mechanisms. This subtask examines the fundamental mechanism leading to the initial adsorption, and seeks to understand the effect of temperature, ammonia slip level, flue gas composition, and ash type on ammonia contamination levels.

\section{Ammonia Adsorption Mechanisms}

The following progress was made in the second quarter of the project:

a) Previous work with pure ammonia resulted in much lower extents of adsorption than in previously published work by Muzio et al. [1995], leading to hypothesis put forward in our last quarterly report that $\mathrm{SO}_{2}$ co-adsorption plays an important synergistic role in enhancing ammonia uptake on fly ash. This quarter we devised a simple experiment to test this hypothesis. Fly ash was placed in a sealed desiccator along with an aqueous ammonia solution of known concentration and the system allowed to equilibrate over one day, after which the ammonium content of the fly ash was measured. Results of this control experiment were then compared to results of an identical experiment in which we also added $20 \mathrm{ml}$ of $\mathrm{SO}_{2}$ to the vapor phase. This first experiment did show that $\mathrm{SO}_{2}$ enhanced ammonia uptake and we are in the process of repeating the experiment to establish reproducibility.

b) In parallel with the static experiments in (a) we are continuing our development of a dynamic adsorption apparatus for studying ammonia uptake in co-flowing $\mathrm{SO}_{2}$ and in the future other flue gas constituents as needed.

c) The on-line ammonia analyzer arrived this quarter and has been set-up and tested by senior research engineer Yuming Gao. It will find use in a variety of dynamic studies of ammonia adsorption and desorption.

d) A new student has been recruited for the project, Zhengwen Li, who is working toward the Ph.D. degree in chemistry and will be advised primarily by Professor Eric Suuberg. For this quarter, Zhengwen has been fully supported by a teaching assistantship in the Chemistry Department at Brown, but has nevertheless begun a literature search on SCR processes and the associated problems with ammonia slip and fly ash utilization. We are also reviewing the literature on the fundamentals of ammonia adsorption, which contains many studies due to the use of ammonia as a standard titrant for acidic sites on solid catalysts. 


\section{Task 6 - Field Validation of Integrated Systems}

\section{Future Field Tests}

Plans for field testing of RRI at Ameren's Sioux Unit \#1 are ongoing. The unit is scheduled to be brought back online mid April following its spring outage, which was initiated in March 2001. During this outage, the RRI and SNCR ports were installed. The RRI demonstration is currently scheduled for June, 2001. Sioux Unit 1 is a $488 \mathrm{MW}$, ten-barrel cyclone furnace with opposed wall firing, which is much larger in size than B.L. England Unit 1.

\section{Results and Discussion}

Specification of RRI injector locations in Ameren's Sioux Unit 1 has been completed. The ports are scheduled to be installed during the spring outage, which is currently in process. In addition, locations for 4 additional ports for SNCR injection have been specified. CFD model predictions indicated that NOx reductions of $30 \%$ should be achievable in this unit with RRI.

Substantial progress has been made on evaluating RRI for PC coal fired units. Evaluations have been performed for several different reagent injection strategies for a front wall fired and an opposed wall fired unit. The evaluations have indicated that application of RRI to PC fired units will be significantly more challenging than in cyclone fired furnaces. The NOx reduction achieved with RRI is highly dependent on the residence time, local gas temperature and local gas composition encountered by the reagent as it passes through the furnace. Good NOx reduction requires injecting the reagent into targeted regions within the furnace and thus the "optimal" injection strategy may be furnace dependent. The best performance achieved so far has involved a combination of in-burner injection and wall injection, which yielded a NOx reduction of $18 \%$ in the front wall fired unit.

Fundamental development work is continuing on the corrosion probe for monitoring waterwall wastage. The focus of the effort in this quarter has been twofold. First, substantial effort has been invested on developing a test procedure for laboratory scale experiments to quantitatively compare measured corrosion rates and corrosion rates predicted by the corrosion probe. The purpose of these tests is to calibrate the ECN readings from the corrosion probe against measured corrosion. As described above, developing these procedures has proven to be more challenging than originally thought. The second focus of our efforts during the last quarter has been to improve the probe design and sub-components in order to make the probe more operator and field friendly. The calibration tests and probe re-design will be completed prior to the next set of field tests, which are scheduled for Summer, 2001.

During the last quarter work was started on investigating soot generation and its impact on boiler performance. Preliminary tests of the soot model within our CFD code have been performed. In addition, initial shakedown tests have been conducted with the measurement equipment that will be used to verify the generation of soot for low NOx firing conditions in a pilot scale furnace. 
The Fly Ash study being performed by Prof. Hurt at Brown University has provided useful data on the adsorption of ammonia onto fly ash. Previous work within this program with pure ammonia resulted in much lower than expected extents of adsorption, leading to the hypothesis put forward in our last quarterly report that $\mathrm{SO}_{2}$ co-adsorption plays an important synergistic role in enhancing ammonia uptake on fly ash. During this quarter, controlled experiments that included $\mathrm{SO}_{2}$ in the simulated flue gas were performed. These tests indicate that $\mathrm{SO}_{2}$ does enhance ammonia uptake. Additional tests are planned to establish the reproducibility of this result. Recent interaction with industry groups has highlighted the need to consider a set of experiments to pursue other aspects of ammonia adsorption. The understanding of ammonia adsorption on ash and our ability to manage it is hindered by the complex nature of the ash / ammonia association. It likely involves a spectrum of chemical species, including chemisorption on acidic sites, physical adsorption on carbon, and physical deposition of aerosol particles. We are currently considering a series of experiments involving pure compounds (e.g. ammoniumbisulfate) to better understand the adsorption and desorption behavior of these different ammonium species. Industry groups working on the ammonia problem have advised us of the need for these type of experiments as the field goes forward toward practical solutions.

\section{Conclusions}

Good progress has been made on several fronts during the last three months. In particular:

- The injector locations for a RRI design have been specified for a cyclone fired utility boiler in which a field test will be performed during Summer, 2001. Evaluations of RRI designs for two PC fired utility boilers have been performed. Initial results indicate the application of RRI to PC units will be more challenging than for cyclone fired units.

- Test procedures for calibrating the corrosion probe to monitor water wall wastage are being established. Preliminary modeling and experimental studies on the impact of soot generation for low NOx firing conditions have been concluded.

- A set of controlled experiments for ammonia adsorption onto fly ash in the presence of sulfur have been performed that indicate the sulfur does enhance ammonia uptake.

Plans for the next quarter include: continued evaluation of RRI for cyclone and PC fired utility boilers, as well as a field test of RRI in $488 \mathrm{MW}$ cyclone fired furnace; completing the calibration tests of the corrosion probe and performing a field test in a utility boiler with the corrosion probe; further improvements to the soot model in our CFD code and pilot scale tests to collect data on soot generation for use in verifying the soot model; finalization of the proposed modification to our SCR catalyst task to include Prof. Baxter; and continued studies on ammonia adsorption onto fly ash and possible removal processes. 


\section{Literature References}

Brown, A.L., "Modeling Soot in Pulverized Coal Flames", M.S. Thesis (Mechanical Engineering), Brigham Young University, Provo, UT, 1997.

Brown, A.L., Fletcher, T.H., Energy Fuels, 1998, Vol 12, pp. 745-757.

Dresselaers, J. and Vandermeulen, W., "Corrosion of Nickel-Coated Cast Iron Containers" in Progress in the Understanding and Prevention of Corrosion, J.M. Costa, ed., The Institute of Materials, Vol. 1., 1993, pp 309-314.

Fletcher, T.H., Kerstein, A.R., Pugmire, R.J., Solum, M.S. and Grant, D.M., Energy Fuels, 1992, vol. 6, pp. 414-431.

Muzio L.J., Kim, E.N., McVickar, M., Qartucy, G.C., McElroy, M., Winegar, P., Proceedings of the Joint EPRI/EPA Symposium on Stationary Combustion NOx Control, Kansas City, 1995.

Park, P.Y., Akiyama, E., Habazaki, H., Kawashima, A., Asami, K. and Hashimoto, K., "The Corrosion behavior of sputter-deposited amorphous Cr-Ni-Mo Alloys in $12 \mathrm{M} \mathrm{HCl}$ ", Corrosion Science, 36 (8), pp 1395-1410, 1994. 